\title{
GESTÃO ESCOLAR: A INFLUÊNCIA DO MODELO DEMOCRÁTICO NA FORMAÇÃO DO ALUNO
}

http://dx.doi.org/10.5902/2318133835556

\author{
Natália Carvalho Rosas Quinquiolo ${ }^{1}$ \\ José Manoel Quinquiolo²
}

Resumo

Neste trabalho busca-se compreender os aspectos da gestão escolar democrática e participativa e sua influência na formação cidadã dos sujeitos, assim como na estruturação de uma sociedade plural pautada no princípio de igualdade. Pontua-se a relação fundamental entre o uso desta modelagem gestora na efetivação de um ensino de qualidade, inclusivo e que instaura o papel social da escola como instituição formadora. Nesse contexto, realizou-se uma revisão bibliográfica, com vistas a clarificar o conceito de gestão escolar participativa e democrática, traçando um breve paralelo com o modelo tradicional, destacando a importância da formação do gestor nessa perspectiva e pontuando os problemas práticos e legais para implantação desse modelo.

Palavras-chave: gestão escolar; gestão democrática; escola.

\section{SCHOOL MANAGEMENT: THE INFLUENCE OF THE DEMOCRATIC MODEL IN STUDENT FORMATION}

\begin{abstract}
The work seeks to understand the aspects of democratic and participative school management and your influence on the citizen formation like as citizen and, consequently, on the construction of a plural society based on the principle, guaranteed by law, of equality. Considers the fundamental relationship between the use of this managerial model in the execution of a quality education, inclusive and that rescues and restores the social role of the school as a training institution. In this context, a bibliographical review was carried out, aiming to clarify the concept of participatory and democratic school management, drawing a brief parallel with the traditional model, highlighting the importance of the manager's training in this perspective, punctuating the practical and legal problems to implement this model.

Key-words: school management; democratic management; school.
\end{abstract}

\footnotetext{
${ }^{1}$ Faculdade Anhanguera de Taubaté, Brasil. E-mail: natalia.quinquiolo@usp.br.

2 Faculdade Anhanguera de Taubaté, Brasil. E-mail: quinquiolo@uol.com.br.

\begin{tabular}{|l|l|l|l|l|l} 
Regae: Rev. Gest. Aval. Educ. & Santa Maria & v. 8 & n. 17 & Pub. contínua 2019 & p. 1-8
\end{tabular}
}




\section{Introdução}

elo presente trabalho busca-se compreender a transformação da gestão escolar, investigando se tal processo transicional, de autoritário para democrático, influencia a formação dos estudantes, objetivando analisar as nuances da gestão participativa em contraponto à gestão tradicional, identificando como ela pode ser importante para os processos escolares e para a comunidade escolar como um todo. Cury (2007) destaca a importância da gestão participativa ao pontuar que a escola pública não pode ser vista como uma empresa por oferecer à população a educação como um bem público e, por essa razão, é imprescindível que se abra ao diálogo, buscando caminhos a democratização da escola brasileira através desse novo modelo gestor. É fundamental que no processo gestor da escola haja uma valorização do indivíduo e dos processos a ela relacionado ao invés do foco no capital, como ocorre em empresas geridas no modelo tradicional, rigidamente hierárquico e autoritário.

Silva (2009) destaca que democratizar a gestão na escola permite-se que se ofereça um ensino de qualidade, que retome a função social das instituições de ensino, permitindo a formação de alunos críticos que atuarão de forma consciente na sociedade de acordo com o que foi ensinado, em consonância com o que é assegurado por lei no nosso país.

Nessa perspectiva, buscamos definir o que é gestão participativa no âmbito escolar e esclarecer a importância de inserir a comunidade escolar no processo gestor, contribuindo assim para a formação dos indivíduos e, consequentemente, da melhoria da sociedade, considerando que a educação se pauta em um princípio de igualdade e de pluralidade. A pesquisa volta-se então a artigos e trabalhos que discorram sobre modelos gestores das escolas, públicas e particulares, no território brasileiro.

Para que possamos identificar os modelos atuais de gestão no nosso país, esclarecendo as diferenças entre modelos autoritários e democráticos, investigando se 0 segundo é de fato um fator importante na formação integral dos alunos. $O$ presente trabalho buscou, por meio de uma pesquisa qualitativa e descritiva de revisão bibliográfica, obter subsídios teóricos para compreender se ao optar por um modelo de gestão participativo e democrático, a escola atua de forma significativa na formação de alunos cidadãos, analisando os aspectos da gestão escolar participativa compreendendo sua influência na formação dos estudantes.

\section{Gestão democrática e participativa}

A escola, no Brasil e no mundo, tem enfrentado mudanças significativas em sua concepção e administração, buscando resgatar seu papel como entidade fundamental na construção social dos indivíduos. Tais mudanças podem ser observadas nos mais diversos aspectos institucionais; seja na busca por abordagens de ensino mais atuais, conectadas com a realidade contemporânea, ou seja, no aperfeiçoamento de processos que de forma direta ou indireta, afetam a todos dentro da instituição.

Para tanto, o setor administrativo na escola também precisou adaptar-se as novas realidades, como reitera Barroso (2013) ao afirmar que a administração escolar atravessa uma profunda fase de transformação, redefinindo o conceito de escola, reforçando e reconhecendo sua autonomia e principalmente, adotando modalidades de gestão 
adaptadas as mais diversas situações as quais a escola enfrenta. Hoje, o diretor não é somente o administrador, mas também o mediador das inúmeras situações que ocorrem na escola e cabe a ele o papel de agregar e unificar os sujeitos da instituição.

Se antes havia uma divisão marcada e bastante separada de administração e pedagógico, atualmente percebe-se que ambos atuam de forma conjunta dentro da escola, devendo atuar de forma alinhada com o objetivo de formar alunos cidadãos, culminando numa gestão democrática e participativa. Buscando definir o que é gestão democrática frente a conceitos de natureza política e social da questão, Dourado (2013) afirma que

a gestão democrática é entendida como processo de aprendizado e luta política que não se circunscreve aos limites da prática educativa mas vislumbra, nas especificidades dessa prática social e de sua relativa autonomia, a possibilidade de criação de canais de efetiva participação e de aprendizado do "jogo" democrático e, consequentemente, do repensar das estruturas de poder autoritário que permeiam as relações sociais e, no seio dessas, as práticas educativas. (p. 97)

Gracindo (2012), corrobora tal afirmativa pontuando que o processo gestor em uma instituição de ensino possui aspectos diferentes daqueles de uma organização empresarial pois tem como essência a educação e a formação dos sujeitos envolvidos, considerando sua participação social. Esse modelo deve, portanto, incorporar fundamentos da gestão democrática afim de ampliar a participação dos sujeitos e dos segmentos escolares, justificando administração ligada não só aos aspectos burocráticos, mas também as práticas educativas tendo como objetivo a formação crítica e social dos indivíduos.

Podemos, portanto, perceber que a gestão democrática vai além do processo de eleger a equipe gestora e de forma ampla, abrange os aspectos de inclusão e promoção da efetiva participação da comunidade escolar na instituição. Ela permite que todos os sujeitos da comunidade escolar sejam ativos na construção da escola, reforçando seu caráter social. Aliás, é fundamental que isso ocorra para que de fato alcancemos esse modelo gestor.

\section{Gestão democrática e participativa na escola}

$\mathrm{Na}$ concepção de gestão democrática na escola, Silva (2009) destaca que não é um processo fechado em si, representando uma forma estática de atuação mas uma forma para que a instituição escolar consiga desenvolver um trabalho, não só no âmbito administrativo e sim de forma ampla com qualidade para todos os envolvidos, dando a escola uma função não só tecnicista, mas também social, com uma perspectiva crítica da sociedade e dos conteúdos por ela trabalhados.

A gestão democrática e participativa difere do modelo tradicional de gestão escolar por permitir o envolvimento de professores, funcionários, alunos e pais na construção da identidade da instituição, bem como das regras e da administração de forma geral, como demonstra Lück (2012) ao defender que 
a institucionalização da democracia, associada ao aprimoramento da eficiência e da qualidade da educação pública, tem sido uma força poderosa a estimular o processo de mudanças na forma de gerir escolas no Brasil. A participação da comunidade escolar, incluindo professores, especialistas, pais, alunos, funcionários e gestores das escolas, é parte desse esforço, que promove o afastamento das tradições corporativas e clientelistas, prejudiciais à melhoria do ensino, por visaram ao atendimento e a interesses pessoais e de grupos. (p. 15)

Neste sentido, cabe a equipe gestora da escola promover ações que permitam o envolvimento da comunidade escolar de maneira efetiva, com objetivos educacionais claros. A promoção da participação deste sujeito deve então buscar, de acordo com Lück, (2013) promover o desenvolvimento do ser humano como ser social, a consequente transformação da escola como instituição social dinâmica e aberta, desenvolvimento do comunitarismo e da coletividade, além do trabalho cooperativo, alcançando assim elevados padrões do ensino, o envolvimento da família no processo político pedagógico escolar e uma maior integração entre currículo escolar e realidade. A autora ressalta inclusive que a gestão educacional interfere diretamente na qualidade do ensino, pois é através dela que a instituição promoverá unidade, consistência e coerência a partir dos seus ideais, porém, sem ser um modelo fechado e sim um sistema dinâmico, que visa a melhoria das ações e processos educacionais voltados para a formação dos indivíduos.

Ferreira (2000) demonstra a importância da gestão democrática na educação ao dizer que ela implica em colocar a educação a serviço de novas finalidades, buscando, portanto, a construção de um futuro mais compromissado com a humanidade e mais distante do quadro atual, imerso em caos e barbárie. Para tanto, deve-se então focar-se não só nos objetivos finais, mas sim nas pessoas e em suas manifestações, proporcionando oportunidades e trabalho cooperativo ao invés de metas e resultados.

No Brasil, a própria constituição federal de 1988, assegura que a escola deve promover a igualdade e pluralidade, respeitando-se os diferentes e suas diferenças: "A educação, direito de todos e dever do Estado e da família, será promovida e incentivada com a colaboração da sociedade, visando ao pleno desenvolvimento da pessoa, seu preparo para o exercício da cidadania e sua qualificação para o trabalho". (Brasil, 1988).

Se temos como princípio fundamentado uma educação de qualidade que permita a formação de um sujeito capaz de atuar criticamente na sociedade, é imprescindível que o modelo gestor se encontre alinhado. Cabe reiterar, como já foi abordado, que nesta concepção participativa, a gestão necessita do envolvimento real da comunidade escola, sem que caiba somente ao gestor (diretor ou coordenador) a responsabilidade pela instituição. Temos nessa perspectiva, uma responsabilidade compartilhada por aqueles que compreendem a importância da sua atuação na construção da sociedade, dentro e fora da escola.

Entretanto, conforme ressalta Dourado (2007), os programas federais de educação básica apresentam concepções distintas e até antagônicas, realçando o cenário contraditório das ações governamentais. Gracindo (2012) compactua com tais pensamentos ao afirmar que a legislação no Brasil fornece base para a implantação da gestão democrática nas escolas, pela LDB, ao determinar que todos os sujeitos escolares, sejam eles professores ou não, devem participar da construção do projeto político-pedagógico da instituição de ensino, além da implementação de conselhos 
escolares que permitam maior participação da comunidade nas decisões da escola. 0 autor pondera ainda que mesmo previsto na legislação, a implementação deste modelo gestor esbarra em contradições legais, pois não há normas e regras claras que norteiem estas mudanças e, portanto, "vem sendo desenvolvida de variadas formas e a partir de diferentes denominações: gestão democrática, gestão participativa, gestão compartilhada, co-gestão, dentre outras" (Gracindo, 2012, p. 135)

Diante destas perspectivas, percebemos que o Brasil, apesar de buscar formas de aplicação de uma gestão realmente democrática, esbarra na própria burocracia ao tentar implementar tal modelo, distanciando a realidade do que é assegurado legalmente.

\section{Desafios da implementação do modelo democrático de gestão escolar}

Somado aos entraves e impasses burocráticos, a implantação da gestão democrática esbarra na falta de interesse dos professores e na inviabilidade dos gestores em promover a participação dos mesmos, gerando uma falsa participação que considera somente a presença física dos profissionais, sem que haja uma ação efetiva por parte dele. Isso ocorre principalmente pois as proposições feitas pela gestão muitas vezes são vazias e já veem pré-determinadas para a comunidade, que não possui voz ativa na decisão. Esse comportamento excludente gera um ressentimento que se agrava, aumentando o desinteresse na participação, pois no fim, a decisão muitas vezes já está tomada. Outra situação recorrente ocorre quando a decisão é tomada coletivamente, mas não há envolvimento.

Entre as nuances dessa dicotomia entre gestão tradicional e gestão participativa, Gutierrez e Catani (2013) afirmam que os modelos de gestão tidos como não tradicionais estão intimamente relacionados com a reestruturação do espaço escolar, principalmente nos aspectos sociais da mesma, estabelecendo relações justas e igualitárias, tendo como princípio o fomento ao desenvolvimento integral de cada indivíduo, englobando aspectos pessoais, técnicos e intelectuais. Os autores consideram ainda que este modelo gestor é responsável por permitir uma maior efetividade coletiva dando aos membros autonomia nas decisões e ações individuais. Declaram que essa nova perspectiva gestora "procura trilhar o caminho inverso das organizações burocráticas, onde a infantilização dos membros viabiliza o controle heterônomo, a manipulação e a alienação" (p. 81).

De nada adianta participar verbalmente em reuniões e conselhos, é necessário agir para alcançar o que foi combinado. Implantar um modelo gestor efetivamente democrático e participativo é sinônimo de descentralização do poder. Lück (2013) afirma que as questões participativas apresentam-se de forma mais ampla do que somente estar presente pois implica em dividir, "compartilhando responsabilidades por decisões tomadas em conjunto como uma coletividade e o enfrentamento dos desafios de promoção de avanços, no sentido de melhoria continua e transformações necessárias" (p. 44).

A própria autora já afirmara em publicação anterior (Lück, 2012), que a gestão escolar participativa demanda uma mudança no método de orientação, coordenação e direção do trabalho escolar pois faz-se necessário atuações sistematizadas, organizadas e planejadas de forma dinâmica e flexível, evitando que os sujeitos participativos nessas ações se sintam oprimidos. Percebe-se então a necessidade de inclusão da comunidade de forma responsável, com o poder participativo sem que haja supressão de direitos e imposição de ideias. 
Para alcançar tal modelo participativo, o gestor necessita de formação especifica em três níveis:

\begin{abstract}
Um primeiro nível voltado para a discussão dos marcos teóricos que clarifiquem: i) o entendimento das políticas educacionais no contexto sóciopoliticocultural que as engendram, bem como de seus desdobramentos nos diversos níveis e instâncias do poder público, visando à instrumentalização para uma intervenção no plano político, pedagógico e curricular; ii) o entendimento da escola como uma construção histórica e sócio-cultural e, portanto, em permanente mudança; iii) o entendimento dos parâmetros que orientam os processos de gestão educacional, considerando as relações entre o mundo do trabalho, da cultura e as relações sociais. O segundo nível contemplaria o desenvolvimento da capacidade de interlocução com os diferentes atores do campo educacional, na construção de processos pedagógicos nas instituições educativas ou nos movimentos sociais, pautados pela ética e pelo compromisso com a democratização das relações sociais [....]. O terceiro nível possibilitaria 0 aproximar-se da discussão teórica sobre 0 planejamento e a gestão dos sistemas de ensino, com vistas à compreensão e apropriação de instrumentais metodológicos e tecnológicos passíveis de serem utilizados nas instituições escolares. (Aguiar, 2000, p. 207)
\end{abstract}

Dessa forma, com base nos princípios norteadores de uma gestão participativa, o gestor atuará de forma segura no alcance da pluralidade, da autonomia e da participação dos sujeitos, através de ações transparentes e democráticas.

\title{
Considerações finais
}

É possível perceber que o Brasil tem buscado alcançar um ensino de qualidade por meio de de propostas e da legislação vigente, que asseguram a formação integral dos alunos. Nessas propostas ressalta-se o estímulo à adoção nas escolas de um modelo de gestão considerado democrático e participativo, abrangendo as mais diversas esferas da comunidade escolar.

A gestão democrática na escola caracteriza-se, principalmente, por permitir que a tomada de decisões e forma de atuação da escola seja definida e conduzida com ampla participação de pais, alunos, funcionários, professores e gestores, para alcançar o objetivo maior de proporcionar aos alunos uma formação crítica, permitindo assim que os mesmos atuem de forma significativa na construção de uma sociedade pautada por princípios que valorizem a pluralidade e a igualdade. Tal modelo, considerado atual e moderno, apresenta-se como sucessor do modelo tradicional, considerado rígido, extremamente hierárquico e autoritário, onde o poder é centralizado.

Nesta linha, a gestão democrática deve valorizar o pluralismo na escola, sempre se pautando no princípio assegurado por lei de igualdade, dando voz a todas as parcelas que compõem a comunidade escolar através da representatividade, atuando para descentralizar o poder com a participação de todos.

Os obstáculos enfrentados por aqueles que já compreendem a importância da participação da comunidade na gestão escolar é a falta de conhecimento e formação para aplicar de forma correta os princípios democráticos. Muitas vezes, a tentativa é feita sem 
que haja consideração real de opiniões, em outras, as decisões já foram tomadas e são somente informadas aos sujeitos, tornando as manifestações verbais desnecessários, gerando um descrédito no modelo.

Outro ponto que desestimula a implantação deste tipo de gestão é a contradição legal que temos em nosso país, somada a burocracia na resolução de questões fundamentais, que culminam num comportamento de resignação que culmina no uso do modelo tradicional, mais fácil. Para tanto, é necessário que os gestores possuam formação básica e continuada de qualidade, para que possam assim compreender a importância do uso da democracia dentro da escola.

\section{Referências}

BARROSO, João. O reforço da autonomia das escolas e a flexibilização da gestão escolar em Portugal. In: FERREIRA, Naura Syria Carapeto (org.). Gestão democrática da educação: atuais tendências e desafios. São Paulo: Cortez, 2013, p. 11-32.

BRASIL. Constituição federal de 1988. São Paulo: Lex, 1988.

CURY, Carlos Roberto Jamil. A gestão democrática na escola e o direito à educação. Rbpae, v. 23, n. 3, 2007, p. 483-495.

DOURADO, Luiz Fernandes. A escolha de dirigentes escolares: políticas e gestão da educação no Brasil. In: FERREIRA, Naura Syria Carapeto (org.). Gestão democrática da educação: atuais tendências e desafios. São Paulo: Cortez, 2013, p. 77-95.

DOURADO, Luiz Fernandes. Políticas e gestão da educação básica no Brasil: limites e perspectivas. Educação e Sociedade, v. 28, n. 100, 2007, p. 921-946.

GODOY, Arilda Schmidt. Introdução à pesquisa qualitativa e suas possibilidades. Revista de Administração de Empresas, v. 35, n. 2, 1995, p. 57-63.

GRACINDO, Regina Vinhaes. O gestor escolar e as demandas da gestão democrática: exigencias, práticas, perfil e formação. Retratos da Escola, 2012, p. 135-147.

GUTIERREZ, Gustavo Luis. CATANI, Afranio Mendes. Participação e gestão escolar: conceitos e potencialidades. In: FERREIRA, Naura Syria Carapeto (org.). Gestão democrática da educação: atuais tendências e desafios. São Paulo: Cortez, 2013, p. 5975.

FERREIRA, Naura Syria Carapeto. Gestão democrática da educação para uma formação humana: conceitos e possibilidades. Em aberto, v. 17, 2000, p. 167-177.

LIMA, Telma Cristiane Sasso; MIOTO, Regina Célia Tamaso. Procedimentos metodológicos na construção do conhecimento científico: a pesquisa bibliográfica. Rev. Katál. Florianópolis, v. 10, 2007, p. 37-45.

LÜCK, Heloisa; FREITAS, Kátia Siqueira de; GIRLING, Robert; KEITH, Sherry. A escola participativa: o trabalho do gestor. Petrópolis: Vozes, 2012.

SILVA, Nilson Robson Guedes. Gestão escolar democrática: uma contextualização do tema. Práxis Educacional, v. 5, n. 6, 2009, p. 91-106. 
Natália Carvalho Rosas Quinquiolo é professora na Faculdade Anhanguera de Taubaté.

Orcid: https://orcid.org/0000-0002-9386-3627.

Endereço: Rua Emilio Winter, 620 - 12030-000 - Taubaté - SP - Brasil.

E-mail: natalia.quinquiolo@usp.br.

José Manoel Quinquiolo é professor na Faculdade Anhanguera de Taubaté.

Orcid: https://orcid.org/0000-0002-1322-1596.

Endereço: Rua Emilio Winter, 620 - 12030-000 - Taubaté - SP - Brasil.

E-mail:quinquiolo@uol.com.br.

Recebido em 8 de novembro de 2018.

Aceito em 21 de dezembro de 2018.

(c) (i) 